\title{
In vitro antimalarial activity evaluation of two ethnomedicinal plants against chloroquine sensitive and resistant strains of Plasmodium falciparum
}

Neelutpal Gogoi ${ }^{1 *}$, Bhaskarjyoti Gogoi ${ }^{2}$ and Dipak Chetia ${ }^{1}$

\begin{abstract}
Background: In this study, we selected two medicinal plants Citrus maxima (Burm.) Merr. and Artemisia nilagirica (C.B. Clarke) Pamp. on the basis of their traditional use in the treatment of fever associated with malaria in Assam (India) and evaluated their antimalarial potential against Plasmodium falciparum strains.

Methods: The properly processed plant parts of C. maxima (Burm.) Merr. and A. nilagirica (C.B. Clarke) Pamp. were extracted with different solvents from nonpolar to polar by cold maceration technique. After that antimalarial activities of the extracts were evaluated against both chloroquine sensitive (3D7) and resistant (RKL-9) strains of P. falciparum using Giemsa staining light microscopy technique. The most active extract(s) was further screened for cytotoxicity potential against murine macrophage RAW264.7 cell line using MTT assay. Then preliminary phytochemical screening and qualitative fingerprint analysis of the active extract(s) were done to check the presence of different secondary metabolites.

Results: From the in vitro study, the hydro-alcoholic extract of C. maxima (Burm.) Merr. and methanol extract of A. nilagirica (C.B. Clarke) Pamp. were found to be the most active against both 3D7 and RKL-9 strains. In the cytotoxicity study, the $\mathrm{CC}_{50}$ values of the active extracts were found to be $>100 \mu \mathrm{g} / \mathrm{ml}$, which suggested the safety of the extracts. Then phytochemical and fingerprint analysis revealed the presence of various important plant secondary metabolites in both the extracts.

Conclusion: The findings of this study confirmed the presence of antimalarial potential of hydro-alcoholic extract of C. maxima (Burm.) Merr. and methanol extract of A. nilagirica (C.B. Clarke) Pamp without having any toxic effect. Both the extracts showed $I C_{50}$ values below $5 \mu \mathrm{g} / \mathrm{ml}$ against 3D7 and RKL-9 strains.
\end{abstract}

Keywords: Malaria, Plasmodium falciparum, Citrus maxima (Burm.) Merr., Artemisia nilagirica (C.B. Clarke) Pamp., Cytotoxicity study, herbal remedy

\footnotetext{
*Correspondence: neelutpalg@gmail.com; neelutpalgogoi@dibru.ac.in

'Department of Pharmaceutical Sciences, Faculty of Science and Engineering,

Dibrugarh University, Dibrugarh, Assam 786004, India

Full list of author information is available at the end of the article
}

\section{Springer Open}

(c) The Author(s). 2021 Open Access This article is licensed under a Creative Commons Attribution 4.0 International License, which permits use, sharing, adaptation, distribution and reproduction in any medium or format, as long as you give appropriate credit to the original author(s) and the source, provide a link to the Creative Commons licence, and indicate if changes were made. The images or other third party material in this article are included in the article's Creative Commons licence, unless indicated otherwise in a credit line to the material. If material is not included in the article's Creative Commons licence and your intended use is not permitted by statutory regulation or exceeds the permitted use, you will need to obtain permission directly from the copyright holder. To view a copy of this licence, visit http://creativecommons.org/licenses/by/4.0/. 


\section{Background}

Different approaches are adopted for the development of new drugs against malaria, where natural compound-based approach is one of the preferable one. It is to mention that several important drug candidates available in the market were originated from plant sources $[1,2]$. The antimalarial drugs, quinine and artemisinin were also isolated from the plant sources based on the information of traditional use [3]. Later several potent semisynthetic and synthetic derivatives of quinine and artemisinin were developed, some of which are still in clinical use and some new derivatives are under developmental stages [4]. Scientists from different regions including India are still searching for the potent antimalarial compounds from various natural resources and have found some plants having antimalarial activity [5]. Being a part of SubHimalayan region, North East (NE) India is rich in plant diversity and various plants of this region have been using in traditional medicine by various ethnic groups of the region. In this study, we selected two ethnomedicinal plants, Citrus maxima (Burm.) Merr. and Artemisia nilagirica (C.B. Clarke) on the basis of their use in the preparation of antimalarial herbal remedy in Assam, a state of NE India. Citrus maxima (Burm.) Merr., commonly known as 'Pumelo' has diverse biological activities like antioxidants, antihyperglycemic/antidiabetic, hepatoprotective, anticancer, antimicrobial/antibacterial, antidepressant, antiaging, cholinesterase and tyrosine inhibition etc. [6-14]. Besides it was also reported that the leaves and fruit parts of C. maxima is also used in the treatment of malaria in Benin which is a highly malaria affected West African region [15]. From the fruit part of Citrus maxima (Burm.) Merr. our group already reported one compound luteolin as a potent antimalarial lead compound against $P$. falciparum using in silico and in vitro analysis [16]. On the other hand, A. nilagirca is reported to have several important biological activities like antioxidant, cytoprotective, anti-inflammatory, antiproliferative, antibacterial, anticancer etc. [17-25]. Apart, this plant also possesses larvicidal, pupicidal, adulticidal and mosquito repellant activity [26-28]. Besides Panda et al. evaluated the antimalarial potency of the different extracts of Artemisia nilagirica (C.B. Clarke) against an African strain (FCR-3) of $P$. falciparum using in vitro technique and found $\mathrm{IC}_{50}$ value $5.76 \pm 0.82 \mu \mathrm{g} / \mathrm{ml}$ of the methanol extract [29]. Based on the previous reports and their use in traditional medicine, it was hypothesized to have active phytoconstituent(s) against the resistant strains of malaria parasites. Hence, in this study, we investigated the antimalarial potency of different extracts of C. maxima and A. nilagirica against chloroquine sensitive (3D7) and chloroquine resistant (RKL-9) strains of $P$. falciparum.

\section{Methods}

\section{Chemicals and reagents}

The analytical reagent grade (EMPARTA ACS grade) solvents like petroleum ether $\left(40-60^{\circ} \mathrm{C}\right)$, toluene, chloroform, ethyl acetate, methanol, ethanol and analytical TLC aluminium plates were purchased from Merck Millipore, Burlington, Massachusetts, USA. The different analytical grade (AR) chemicals like sodium bicarbonate, HEPES buffer, D-glucose, D-sorbitol, formic acid, phosphate buffer solution 10X (PBS), Giemsa stain, sodium pyruvate, dimethyl sulfoxide (DMSO) and plastic wares used in the biological activity screening were purchased from HiMedia Pvt. Ltd., Mumbai, India. Molecular biology grade Fetal bovine serum (FBS), gentamycin, amphotericinB, penicillin, streptomycin, 3-(4,5-dimethylthiazol-2-yl)-2,5diphenyl tetrazolium bromide (MTT), RPMI-1640 (Roswell Park Memorial Institute-1640), DMEM (Dulbecco's Modified Eagle's medium) were purchased from GibcoBRL, Life Technologies Inc., Gaithersburg, MD 208849980, USA and Sigma Aldrich, St. Louis, MO, USA. The marker compound and standard drug, namely, quercetin (HPLC grade $\geq 95 \%$ ) and chloroquine phosphate (Certified Reference Material grade) were purchased from SigmaAldrich, St. Louis, MO, USA.

\section{Plant materials}

The information regarding the use of different plants as herbal remedies for the treatment of fever associated with malaria was collected by interviewing local practitioners in the form of questionnaires and from local books.

Herbariums of the two selected plants (Voucher specimen no. DU/DRS/HRB/NG/2018-19/FS-01 and DU/ DRS/HRB/NG/2018-19/FS-05) were prepared according to standard procedure and sent to Botanical Survey of India, Shillong for identification and authentication. Then the plant parts used in the preparation the traditional herbal remedy were collected and processed according to the guideline of Good Agricultural and Collection Practice of WHO [30]. The processed plant materials were coarsely powdered with a mechanical grinder and stored in airtight containers.

\section{Extraction of the plant materials}

The extraction of the powdered plant materials was carried out using cold maceration technique using petroleum ether $\left(40-60^{\circ} \mathrm{C}\right)$, chloroform, ethyl acetate, methanol and hydro-alcoholic (1:1) solvent system. Besides, one sample from each plant were prepared as per the traditional practices. In the cold maceration, about $500 \mathrm{~g}$ plant material was taken with $3 \mathrm{l}$ of solvent and kept for $72 \mathrm{~h}$ with occasional shaking [31]. After that, the solvents were removed under reduced pressure at low temperature using a rotary evaporator (IKA Rotary 
Evaporator RV $8 \mathrm{~V}$ ). In the case of the hydro-alcoholic extract, the water part was removed by lyophilisation of the sample using laboratory freeze dryer (IIC Industrial Corporation). The extracts were preserved in glass sample bottles and kept in $-20^{\circ} \mathrm{C}$ for further use. The extracts were prepared at ratio of 1:6 during cold maceration process. The yields of the extracts of $C$. maxima were found to be $0.262 \%, 0.562 \%, 2.882 \%, 1.151 \%$, $8.305 \%$ and $0.167 \% \mathrm{w} / \mathrm{w}$ with petroleum ether (40$60^{\circ} \mathrm{C}$ ), chloroform, ethyl acetate, methanol, hydroalcoholic and traditional solvent system respectively. Similarly, in case of A. nilagirica, the yields of the extracts were found to be $0.757 \%, 1.627 \%, 1.891 \%, 2.062 \%$, $1.770 \%$ and $0.215 \% \mathrm{w} / \mathrm{w}$ with petroleum ether (40$60^{\circ} \mathrm{C}$ ), chloroform, ethyl acetate, methanol, hydroalcoholic and traditional solvent system respectively.

\section{In vitro antimalarial screening of the extracts Preparation of standard and test samples}

For this study, $1 \mathrm{mg} / \mathrm{ml}$ stock solutions of the extracts were prepared by using incomplete RPMI-1640 media containing $0.5 \%$ DMSO. Chloroquine phosphate was used as standard drug in this study and prepared $100 \mu \mathrm{g} /$ $\mathrm{ml}$ stock using the same protocol as used for extracts for further use.

\section{In vitro culture of malaria parasites}

The chloroquine sensitive (3D7) and chloroquine resistant (RKL-9) strains of the malaria parasite P. falciparum were obtained from the Parasite Bank of National Institute of Malaria Research (Indian Council of Medical Research), New Delhi. The strains of $P$. falciparum were maintained in fresh A+ erythrocytes suspended in RPMI-1640 medium supplemented with $25 \mathrm{mM}$ HEPES, $1 \%$ D-glucose, $0.23 \%$ sodium bicarbonate, gentamycin $(40 \mathrm{mg} / \mathrm{ml})$, amphotericinB $(0.25 \mathrm{mg} / \mathrm{ml})$ and $10 \%$ heat-inactivated $\mathrm{AB}+$ serum at $37^{\circ} \mathrm{C}$ and $5 \% \mathrm{CO}_{2}$ environment [32,33]. After every $24 \mathrm{~h}$, the used medium was replaced with fresh medium supplemented with $10 \%$ heat-inactivated $\mathrm{AB}+$ serum and the parasitemia level was maintained below $2 \%$.

\section{Antimalarial activity screening \& determination of $I C_{50}$ values}

The antimalarial screening of the extracts was carried out against both 3D7 and RKL-9 strain of P. falciparum by Giemsa staining light microscopy method. For antimalarial testing, initially the asynchronous $P$. falciparum parasites were synchronized to obtain only the ring stage parasitized cells by treating with $5 \% \mathrm{D}$-sorbitol [34]. The initial ring stage parasitemia was maintained at $0.5 \%$ in $4 \%$ haematocrit using complete medium and fresh $\mathrm{A}+$ erythrocytes before using in the screening. For screening, test and standard drugs were taken in nine different concentrations by two fold serial dilutions for both the 3D7 and RKL-9 strains in 96 well plates. The concentration ranges for test drug and standard drug were 50 to $0.19 \mu \mathrm{g} / \mathrm{ml}$ and 5 to $0.019 \mu \mathrm{g} / \mathrm{ml}$ respectively. All the treatments were performed in triplicates. Then parasitized blood was added to the wells of 96-well plate containing $100 \mu \mathrm{l}$ of test and standard samples to carry out the assay. The plates were incubated at $37^{\circ} \mathrm{C}$ in an environment of $5 \% \mathrm{CO}_{2}$ for $36-40 \mathrm{~h}$ in a $\mathrm{CO}_{2}$ incubator. After the incubation period, blood smears were prepared in glass slide from each well and fixed by treating with methanol. The slides were stained with $10 \%$ Giemsa stain prepared in $1 \%$ phosphate buffer solution (PBS). After that number of schizonts (3 or more merozoites containing) per 100 asexual parasites were counted under a light microscope (Leica DM1000) at 1000X (oil emersion) magnification [35]. The percentage inhibition for each concentration was calculated by the following equation:

$$
\begin{aligned}
\% \text { Inhibition }= & 1-\frac{\text { no.of schizonts in test }}{\text { no.of schizonts in negative control }} \\
& \times 100
\end{aligned}
$$

Finally, the $\mathrm{IC}_{50}$ values were calculated by plotting nonlinear regression curve between log dose vs percentage (\%) inhibition using GraphPad Prism (GraphPad Prism v.7 San Diego, California, USA). Based on the obtained $\mathrm{IC}_{50}$ values, the extracts were categorized in to active $(<10 \mu \mathrm{g} / \mathrm{ml})$, intermediate $(10-25 \mu \mathrm{g} / \mathrm{ml})$ or inactive (>25 $\mu \mathrm{g} / \mathrm{ml}$ ) categories [36].

\section{In vitro cytotoxicity study}

The most active extract obtained for each plant from the in vitro antimalarial study were further taken for in vitro cytotoxicity study using MTT assay [37]. The study was carried out against normal murine macrophage RAW264.7 cell line. Approximately, $1 \times 10^{4}$ cells $/ \mathrm{ml}$ were cultured in DMEM (Dulbecco's Modified Eagle's medium) media supplemented with $2 \mathrm{mML}$-glutamine, $1 \mathrm{mM}$ sodium pyruvate, 10\% FBS (Fetal Bovine Serum), penicillin (100 units $/ \mathrm{ml})$, streptomycin $(10 \mu \mathrm{g} / \mathrm{ml})$ and allowed to incubate at $37^{\circ} \mathrm{C}$ in a humidified $5 \% \mathrm{CO}_{2}$ environment. After $80 \%$ cell confluency, the cells were treated with different concentrations $(50,100,200$ and $500 \mu \mathrm{g} / \mathrm{ml}$ ) of the selected test extracts and incubated for $24 \mathrm{~h}$. Cells without any treatment were considered as control. After $24 \mathrm{~h}$ incubation, $0.5 \mathrm{mg} / \mathrm{ml}$ MTT was added to each well of the plates and incubated for a further $5 \mathrm{~h}$. After the completion of the incubation, formed formazone complexes were dissolved properly in MTT solvent and the absorbance was taken at $570 \mathrm{~nm}$ using a microplate reader (Multiskan ${ }^{\mathrm{TM}}$ FC Microplate Photometer). The experiment was performed in triplicates and the percentage of cell viability was calculated for each 
concentration and compared to control cells without any treatment. Finally, $\mathrm{CC}_{50}$ (cytotoxic concentration) were determined for the test extracts.

\section{Phytochemical and qualitative fingerprint analysis}

The various biological activities shown by plant extracts are mainly due to the presence of the different secondary metabolites like alkaloids, flavonoids, glycosides, terpenoids, saponins, steroids, tannins etc. [38]. The active extract from each plant was analysed by chemical reagents to detect the presence of those secondary metabolites using standard procedures as described in the earlier study [39].

The qualitative fingerprint analysis of an extract under the controlled environment is one of the quality control parameters for herbal products [40, 41]. In this study, the qualitative fingerprints of the active extracts were developed using HPTLC densitometry analysis under control environment of temperature and humidity. The study was carried out by using Camag TLC Scanner 4, semiautomatic sample spotter Linomat 5, UV visualization cabinet (deuterium, tungsten and mercury lamp), $100 \mu \mathrm{l}$ Hamilton dosage syringe, TLC aluminium plate precoated with silica gel $60 \mathrm{~F}_{254}(10 \mathrm{~cm} \times 10 \mathrm{~cm})$ and glass twin trough chamber $(10 \mathrm{~cm} \times 10 \mathrm{~cm})$.

Initially, stock solutions of the marker compound (quercetin for A. nilagirica)/semi-purified fraction for $C$. maxima $(1 \mathrm{mg} / \mathrm{ml})$ and active extracts $(10 \mathrm{mg} / \mathrm{ml})$ were prepared in their respective solvents by sonicating for $15 \mathrm{~min}$. Then the samples were centrifuged at $2000 \mathrm{rpm}$ for $5 \mathrm{~min}$ and the supernatants were transferred to the sample vials by filtration for further use.

The experiment was carried out at a temperature of $25 \pm 2{ }^{\circ} \mathrm{C}$, relative humidity $55 \%$. In the TLC plate $(10$ $\mathrm{cm} \times 10 \mathrm{~cm}), 2 \mu \mathrm{L}$ of the marker compound or semi- purified fraction in duplicate and $4 \mu \mathrm{L}$ of the active extracts in quadruplicate were applied as a band of $8 \mathrm{~mm} \times$ $1 \mathrm{~mm}$ in size at a distance of $8 \mathrm{~mm}$ from the bottom. After applying the sample, the plates were developed using 10 $\mathrm{ml}$ mobile phase composed of toluene: ethyl acetate: methanol: formic acid at a ratio of 3:5:1:0.5 using the glass twin trough chamber $(10 \mathrm{~cm} \times 10 \mathrm{~cm})$. The plates were developed up to a distance of $7 \mathrm{~cm}$ and air-dried at room temperature. Then plates were visualized under UV cabinet at $254 \mathrm{~nm}$ and $366 \mathrm{~nm}$. After that, the plates were scanned at $254 \mathrm{~nm}$ in absorbance mode and at $366 \mathrm{~nm}$ in fluorescence mode using the Camag TLC scanner 4 linked with VisionCAT 2.5 software. During scanning, the slit dimension was kept at $5 \times 0.2 \mathrm{~mm}$ and the scanning speed was employed at $20 \mathrm{~mm} / \mathrm{s}$ [42].

\section{Results}

Identification and small scale extraction of plant materials The plants used in the preparation of herbarium were identified as Citrus maxima (Burm.) Merr. (F: Rutaceae) and Artemisia nilagirca (C.B. Clarke) Pamp. (F: Asteraceae) by Dr. N. Odyuo, Scientist D, Botanical Survey of India, Shillong (Ref no. BSI/ERC/Tech/2019/481 dated 23.09.2019). After completing the extraction process, the highest yield was obtained in hydro-alcoholic solvent system for $C$. maxima whereas highest yield was obtained in methanol solvent for $A$. nilagirica.

\section{In vitro antimalarial activity}

The slides prepared from each well were observed under the light microscope and the number of infected erythrocytes were counted within a particular area. From the infected erythrocytes, the number of parasites with schizont stage were calculated and used for determination of \%

Table $1 I_{50}$ values of the plant extracts against 3D7 and RKL-9 strains of $P$. falciparum

\begin{tabular}{|c|c|c|c|c|}
\hline \multirow{2}{*}{$\begin{array}{l}\text { SI. } \\
\text { No. }\end{array}$} & \multicolumn{2}{|l|}{ Samples } & \multicolumn{2}{|l|}{$I C_{50}{ }^{a}(\mu \mathrm{g} / \mathrm{ml})$} \\
\hline & Plant & Solvent for extraction & $3 \mathrm{D7}$ & RKL-9 \\
\hline \multirow[t]{6}{*}{1} & C. maxima & Petroleum ether (PE) & $27.25 \pm 1.52$ & $42.70 \pm 0.14$ \\
\hline & & Chloroform (Chlor) & $7.20 \pm 0.16$ & $11.74 \pm 0.01$ \\
\hline & & Ethyl acetate (EA) & $5.87 \pm 0.19$ & $6.19 \pm 0.22$ \\
\hline & & Methanol (ME) & $3.52 \pm 0.32$ & $4.52 \pm 0.19$ \\
\hline & & Hydro-alcoholic (HA) & $3.41 \pm 0.31$ & $4.45 \pm 0.10$ \\
\hline & & Remedy (REM) & $20.77 \pm 1.30$ & $31.19 \pm 2.29$ \\
\hline \multirow[t]{6}{*}{2} & A. nilagirica & Petroleum ether (PE) & $14.24 \pm 0.25$ & $18.65 \pm 0.67$ \\
\hline & & Chloroform (Chlor) & $11.61 \pm 1.26$ & $14.51 \pm 0.26$ \\
\hline & & Ethyl acetate (EA) & $5.22 \pm 0.14$ & $5.75 \pm 0.23$ \\
\hline & & Methanol (ME) & $3.28 \pm 0.08$ & $3.81 \pm 0.34$ \\
\hline & & Hydro-alcoholic (HA) & $3.41 \pm 0.11$ & $5.51 \pm 0.39$ \\
\hline & & Remedy (REM) & $26.51 \pm 1.35$ & $37.86 \pm 3.17$ \\
\hline 3 & \multicolumn{2}{|c|}{ Standard drug (Chloroquine phosphate) } & $0.54 \pm 0.02$ & $0.88 \pm 0.04$ \\
\hline
\end{tabular}

${ }^{\mathrm{a}}$ The $\mathrm{IC}_{50}$ values (Mean $\pm \mathrm{SD}$ ) were calculated from triplicate analysis 
inhibition. The in vitro antimalarial activity of the extracts was determined in the form of $\mathrm{IC}_{50}$ values using nonlinear regression analysis against both 3D7 and RKL-9 strains, and compared with the standard drug chloroquine phosphate (Table 1 \& Fig. 1). The representative photomicrographs of smear observed under the microscope during counting are shown in Fig. 2. From the results, it was observed that in the case of C. maxima the hydro-alcoholic extract (CM-HA) showed the lowest $\mathrm{IC}_{50}$ values $3.41 \pm$ $0.31 \mu \mathrm{g} / \mathrm{ml}$ and $4.45 \pm 0.10 \mu \mathrm{g} / \mathrm{ml}$ against 3D7 and RKL-9 strains respectively. In the case of A. nilagirica, methanol extract (AN-ME) showed the lowest $\mathrm{IC}_{50}$ values $3.28 \pm$ $0.08 \mu \mathrm{g} / \mathrm{ml}$ and $3.81 \pm 0.34 \mu \mathrm{g} / \mathrm{ml}$ against 3D7 and RKL-9 stains respectively.

\section{In vitro cytotoxicity study}

The active extract(s) selected from the antimalarial screening were further analysed for cytotoxicity potential by MTT assay. The methanol extract of $A$. nilagirica (AN-ME) and hydro-alcoholic extract of $C$. maxima (CM-HA) were screened against normal murine macrophage RAW264.7 cell line where \% viability for the methanol extract of $A$. nilagirica was found to be more than $90 \%$ at the maximum dose $500 \mu \mathrm{g} / \mathrm{ml}$ (Fig. 3). On the other hand, the \% viability for the hydro-alcoholic extract of C. maxima was found to be less than $50 \%$ at the maximum dose of $500 \mu \mathrm{g} / \mathrm{ml}$ (Fig. 3). Later $\mathrm{CC}_{50}$ values for both the extracts were determined and found to be more than $100 \mu \mathrm{g} / \mathrm{ml}$ for both the extracts (Fig. 3).
A.

\section{C. maxima extracts against 3D7}

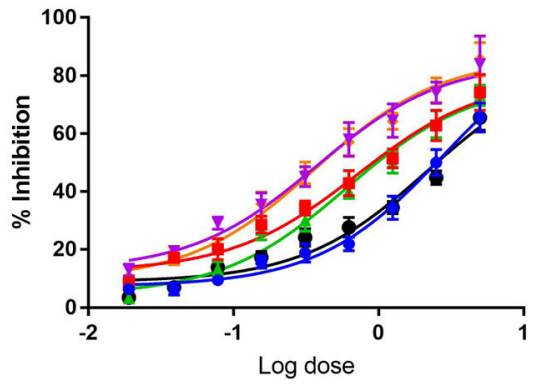

C.

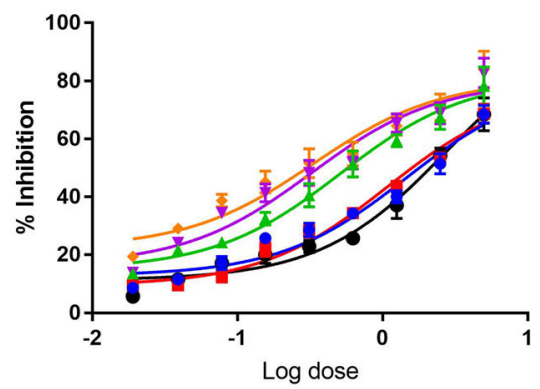

E.

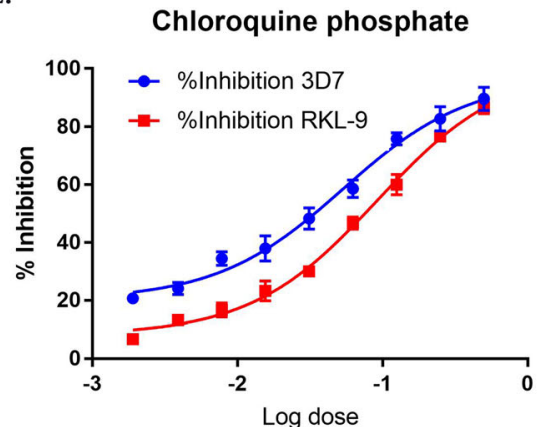

B. C. maxima extracts against RKL-9

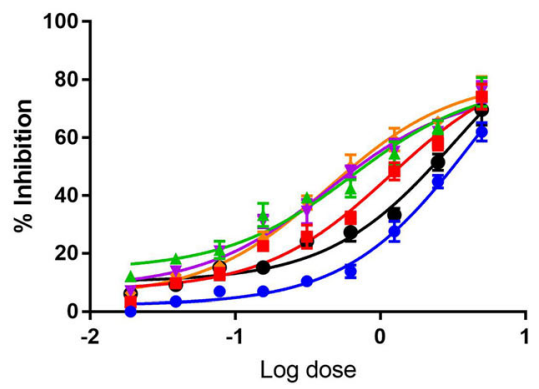

D. A. nilagirica extracts against RKL-9

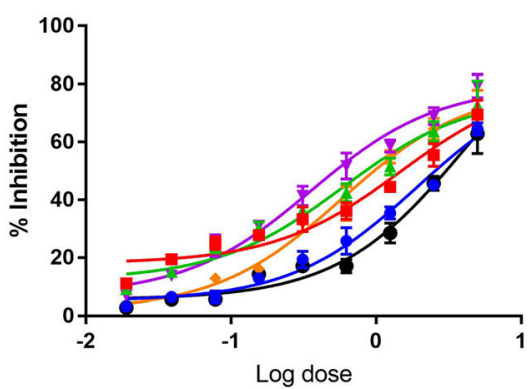

F.

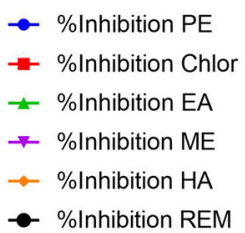

Fig. 1 Calculation of $\mathrm{IC}_{50}$ values by non-linear regression analysis (GraphPad Prism) using nine different concentrations with two-fold serial dilution. For the test extracts the dilution was made from $50 \mu \mathrm{g} / \mathrm{ml}$ to $0.195 \mu \mathrm{g} / \mathrm{ml}$ whereas for the standard drug the dilution was made from $5 \mu \mathrm{g} / \mathrm{ml}$ to $0.019 \mu \mathrm{g} / \mathrm{ml}$. The experiment was performed in triplicates and each value is the mean \pm SD of three replicates 


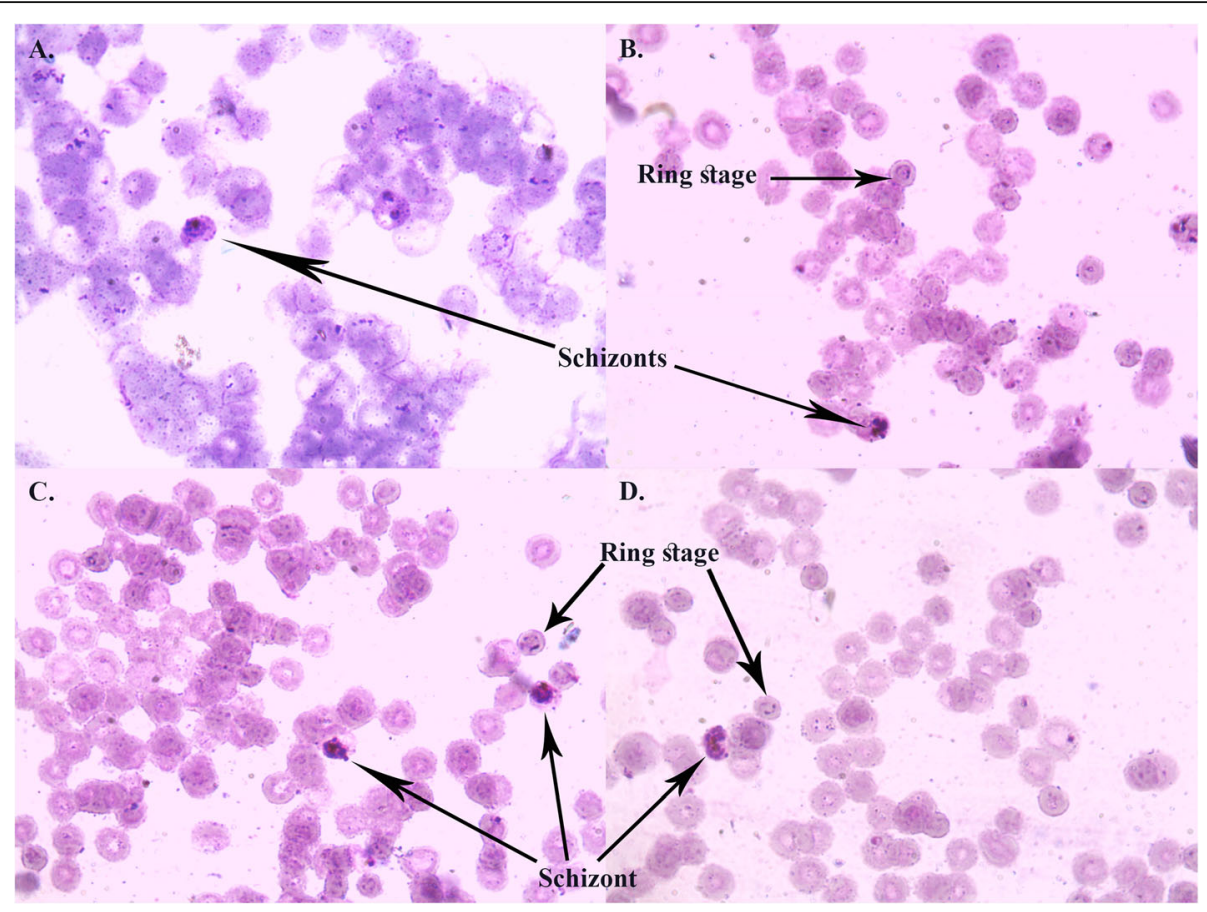

Fig. 2 Representative photomicrographs taken during the observation under light microscope at 1000X (oil emersion) magnification showing infected erythrocytes by different strains of $P$. falciparum; a. 3D7 without treatment, b. 3D7 with treatment $(50 \mu \mathrm{g} / \mathrm{ml})$, c. RKL-9 without treatment and d. RKL-9 with treatment $(50 \mu \mathrm{g} / \mathrm{ml})$

\section{Phytochemical \& fingerprint analysis}

The bioactive potential shown by a plant extract is due to the presence of different plant secondary metabolites in the sample. From the preliminary chemical tests, alkaloids, flavonoids and glycosides were found to be present in the CM-HA extract whereas, alkaloids, flavonoids, tannins and terpenoids were found to be present in the AN-ME extract (Table S1).

The qualitative fingerprint analysis of extract is a standardization process of plant material or plant extract in the absence of known marker or standard compound. The fingerprints of the active extracts were developed under control environmental conditions like temperature and humidity, and found the presence of various types of compounds in the extracts (Figs. 4 and 5). The chromatograms developed after scanning under $254 \mathrm{~nm}$ (absorbance mode) and $366 \mathrm{~nm}$ (fluorescence mode) for each extract revealed the presence of multiple components (based on number of peaks) and their possible quantity (based on the area of the peaks) (Fig. S1 \& S2).

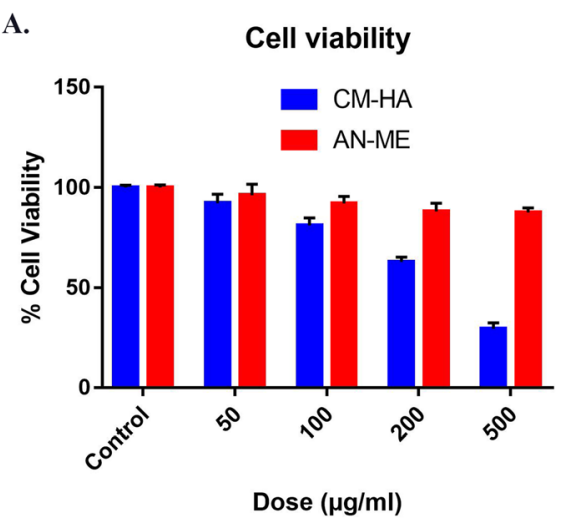

B.

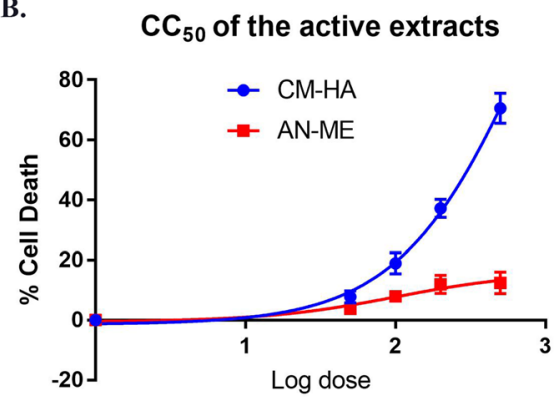

Fig. 3 Cytotoxic effects of the active extracts of C. maxima and A. nilagirica on murine macrophage RAW264.7 cell line; a Cell viability after treatment of $24 \mathrm{~h}$ with the different dose of the extracts. $\mathbf{b}$ Determination of $\mathrm{CC}_{50}$ values of the two extracts (CM-HA and $\left.\mathrm{AN}-\mathrm{ME}\right)$. The experiment was performed in triplicates and each value is the mean \pm SD of three replicates 


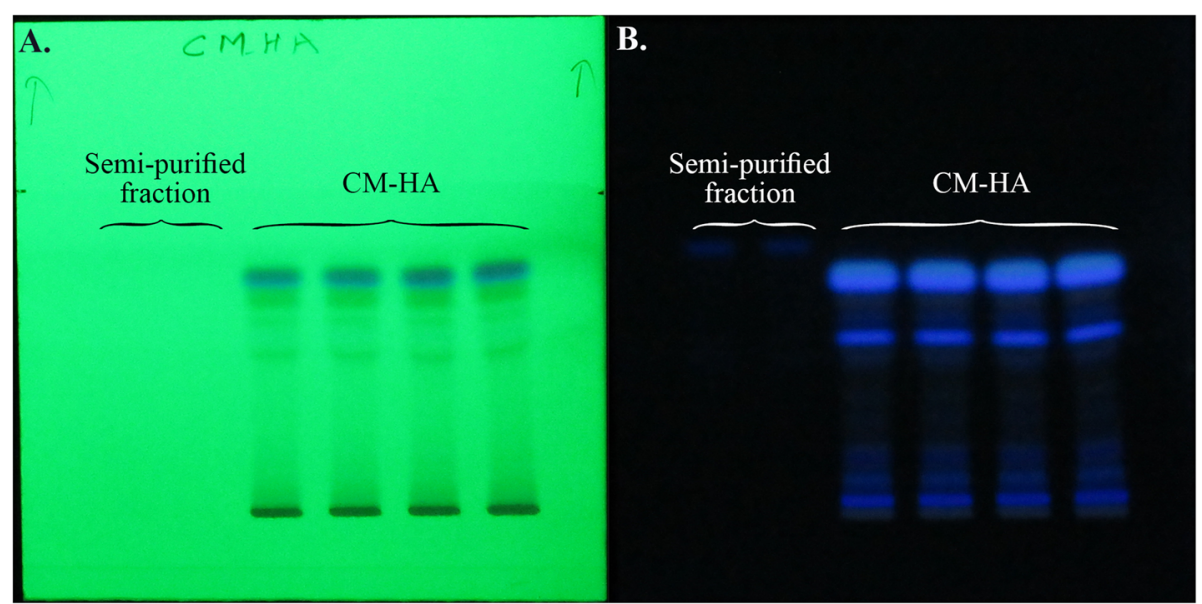

Fig. 4 Visualization of the TLC plates under UV visualizer at $254 \mathrm{~nm}$ and $366 \mathrm{~nm}$ to detect the presence of different plant secondary metabolites of Citrus maxima (Burm.) Merr

\section{Discussion}

The discovery of new antimalarial lead molecule(s) or the development to of antimalarial phytopharmaceutical product(s) from traditionally used plant materials/parts has gained significant importance [43]. For that purpose, the preliminary in vitro antimalarial screening of the plant materials/parts is very essential along with their toxicity assessment against normal mammalian/human cell. Therefore, this study aimed to evaluate the antimalarial potential of the different extracts of the two selected traditionally used plants as well as cytotoxic effect of the active extracts in in vitro conditions. All the extracts obtained from the two plants (C. maxima and $A$. nilagirica) showed the antimalarial activity within different ranges in the form of $\mathrm{IC}_{50}$ values in in vitro antimalarial analysis. From the results, we found that the ethyl acetate, methanol and hydro-alcoholic extracts came under active category $(<10 \mu \mathrm{g} / \mathrm{ml})$ against both 3D7 and RKL-9 strains of P. falciparum. The chloroform extract of $C$. maxima also came under the active category only against the 3D7 strain of $P$. falciparum. However, among the active extracts, in the case of $C$. maxima, the hydro-alcoholic extract showed the best activity with $\mathrm{IC}_{50}$ values $3.41 \pm 0.31 \mu \mathrm{g} / \mathrm{ml}$ and $4.45 \pm$ $0.10 \mu \mathrm{g} / \mathrm{ml}$ against 3D7 and RKL-9 respectively (Table $1)$. Whereas in the case of $A$. nilagirica, the methanol extract showed the best activity with $\mathrm{IC}_{50}$ values $3.28 \pm$ $0.08 \mu \mathrm{g} / \mathrm{ml}$ (3D7) and $3.81 \pm 0.34 \mu \mathrm{g} / \mathrm{ml}$ against 3D7 and RKL-9 respectively (Table 1 ). These two extracts may contain the phytoconstituents which are responsible for

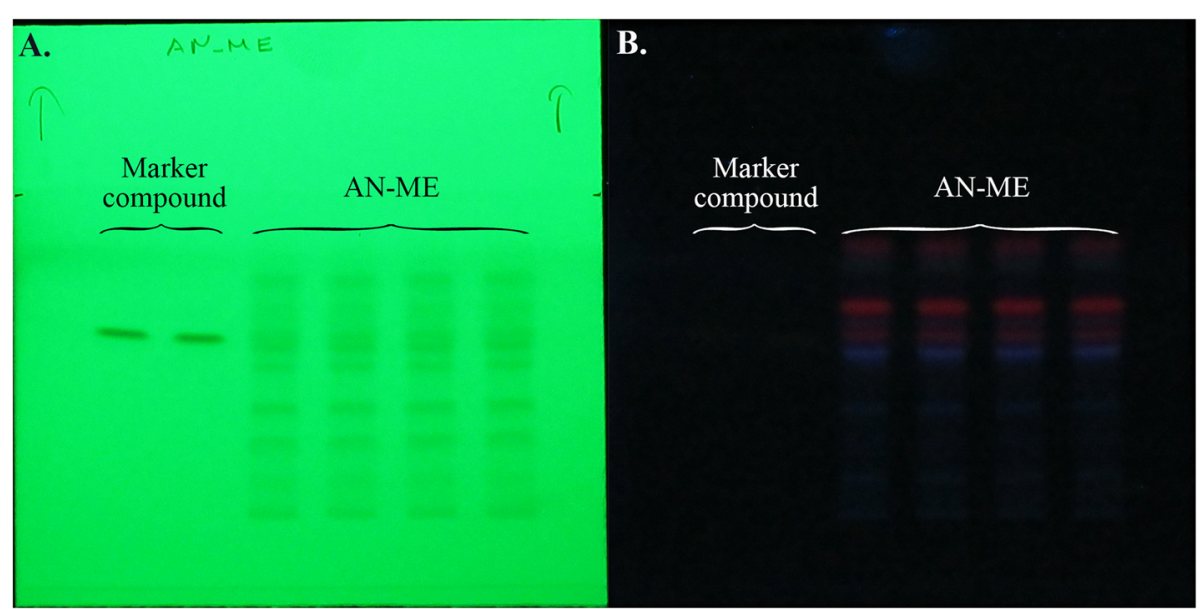

Fig. 5 Visualization of the TLC plates under UV visualizer at $254 \mathrm{~nm}$ and $366 \mathrm{~nm}$ to detect the presence of different plant secondary metabolites of Artemisia nilagirica (C.B. Clarke) Pamp 
strong antimalarial activity against $P$. falciparum strains. The antimalarial activity of the root part of $C$. maxima is not reported till date. But the antimalarial activity of the leaves of $A$. nilagirica was reported by Panda et al. against a different strain of $P$. falciparum where methanol extract was found to be the most active [29]. The preliminary phytochemical screening of the extracts revealed the presence of some important class of plant secondary metabolites like alkaloids, flavonoids and terpenoids. Pan et al., 2018 already reported the antimalarial activity of secondary metabolites like alkaloids, flavonoids and terpenoids [44]. Hence, the potential in vitro antimalarial activity showed by the active extracts (CM-HA and AN-ME) against the two P. falciparum strains may be due to the presence of these important classes of secondary metabolites. Although the $\mathrm{IC}_{50}$ values of these two extracts were not near to the $\mathrm{IC}_{50}$ values of the standard drug chloroquine phosphate $\left(\mathrm{IC}_{50}\right.$ values $0.54 \pm 0.02 \mu \mathrm{g} / \mathrm{ml}$ and $0.88 \pm 0.04 \mu \mathrm{g} /$ $\mathrm{ml}$ against 3D7 and RKL-9 respectively), at extract level the results were satisfactory and can be taken for further study [45]. In the case of both the plants, the samples prepared in the traditional way were found to be either in the intermediate or inactive category. But as they were showing some extent of inhibition in the growth of the parasites hence the traditional way of using these plant parts give some benefits to the patients. The activity of the other extracts also suggests the positive impacts of these plants on the treatment of malaria.

The two active extracts were further examined for their cytotoxicity potential against normal cell line (murine macrophage RAW264.7 cell line) where the methanol extract of $A$. nilagirica (AN-ME) was found to be safe even at a dose of $500 \mu \mathrm{g} / \mathrm{ml}$ with $>90 \%$ cell viability (Fig. 3). But the hydro-alcoholic extract of C. maxima (CM-HA) was found to be toxic at the maximum dose of $500 \mu \mathrm{g} / \mathrm{ml}$ with $<50 \%$ cell viability (Fig. 3). After that, the $\mathrm{CC}_{50}$ values of the extracts were determined where the $\mathrm{CC}_{50}$ value of the $\mathrm{CM}-\mathrm{HA}$ was found to be $817.3 \pm$ $2.4 \mu \mathrm{g} / \mathrm{ml}$ whereas the $\mathrm{CC}_{50}$ value of the $\mathrm{AN}-\mathrm{ME}$ was found to be $>1000 \mu \mathrm{g} / \mathrm{ml}$. Overall both the extracts (CM-HA and AN-ME) were found to be more selective towards $P$. falciparum than normal cells. Besides extracts or compounds with $\mathrm{CC}_{50}>90 \mu \mathrm{g} / \mathrm{ml}$ against normal cell line are considered to be safe and can be taken for further study [46], hence the two test extracts can be utilized for further preclinical studies.

The preliminary phytochemical and fingerprint analysis provide an idea regarding the presence of different plant metabolites in the selected extract [47]. As from the analysis, no known markers were found for both the extracts, the qualitative fingerprints were developed in a controlled environment of temperature and humidity using a suitable mobile phase. The photographs as well the chromatograms developed during the study gave an idea that the CM-HA contained diverse groups of compounds with absorbance and fluorescence characteristics (Fig. 4). The intensities of the bands also indicate the presence of significant amounts of few compounds in the extract. Similarly, the photographs and chromatograms of AN-ME also showed the presence of diverse groups of compounds but the intensity of the bands indicated the presence of those compounds in less quantity (Fig. 5). These two final extracts (CM-HA and AN-ME) were found to be highly active $(<5 \mu \mathrm{g} / \mathrm{ml})$ with the presence of various important secondary metabolites. These active extracts can deliver new/novel lead compound(s) with antimalarial activity as well as can be further utilized for the development of phytopharmaceutical products by fulfilling the criteria of regulatory body like CDSCO (Central Drugs Standard Control Organisation) for global acceptance.

\section{Conclusion}

In this study, we investigated the antimalarial activity of different extracts of two traditionally used medicinal plants C. maxima and A. nilagirica against both chloroquine sensitive (3D7) and chloroquine resistant (RKL-9) strains of $P$. falciparum. From the results obtained from in vitro experiments, it was observed that hydro-alcoholic extract of $C$. maxima and methanolic extracts of A. nilagirica showed the potent activity against the strains of $P$. falciparum without having any toxic effect. The findings of the study will help in identification of active antimalarial lead molecule(s) from the active extracts to develop safe and potent antimalarial drug(s) or phytopharmaceuti$\mathrm{cal}(\mathrm{s})$ by following proper standardization techniques as per the regulatory guidelines.

\section{Abbreviations \\ A. Nilagirica: Artemisia nilagirica (C.B. Clarke) Pamp; C. maxima: Citrus maxima (Burm.) Merr; AN-ME: Methanol extract of A. nilagirica; CM-HA: Hydro- alcoholic extract of C. maxima; RPMI-1640: Roswell Park Memorial Institute- 1640; IC 50 : 50\% inhibitory concentration; PBS: Phosphate buffer solution; DMEM: Dulbecco's Modified Eagle's medium; FBS: Fetal Bovine Serum; $\mathrm{CC}_{50}$ : 50\% cytotoxic concentration; CDSCO: Central Drugs Standard Control Organisation}

\section{Supplementary Information}

The online version contains supplementary material available at https://doi. org/10.1186/s40816-021-00269-1.

\section{Additional file 1}

\section{Acknowledgements}

The authors are thankful to the Department of Pharmaceutical Sciences, Dibrugarh University, Dibrugarh, Assam, India for providing the laboratory facilities to conduct the research work. The Authors also are thankful to the Parasite Bank of National Institute of Malaria Research (Indian Council of Medical Research), New Delhi for providing the malaria parasite strains to carry out the research work. 


\section{Authors' contributions}

NG and DC conceived and designed the experiments; NG \& BG performed the in vitro experiments and analysed the results; NG wrote the manuscript, and BG \& DC reviewed the manuscript. All authors read and approved the final manuscript.

\section{Funding}

The work was supported by University Grants Commission, New Delhi, India under UGC-SAP (DRS-I) [F.3-13/2016/DRS-I (SAP-II)].

\section{Availability of data and materials}

The datasets used and/or analysed during the current study are available from the corresponding author on reasonable request.

\section{Declarations}

\section{Ethics approval and consent to participate}

Not applicable.

\section{Consent for publication}

Not applicable.

\section{Competing interests}

The authors declare that they have no competing interests.

\section{Author details}

'Department of Pharmaceutical Sciences, Faculty of Science and Engineering, Dibrugarh University, Dibrugarh, Assam 786004, India. ${ }^{2}$ Department of Biotechnology, Royal School of Bio-Science, Royal Global University, Guwahati, India.

\section{Received: 15 September 2020 Accepted: 1 April 2021}

\section{Published online: 06 May 2021}

\section{References}

1. Newman DJ, Cragg GM. Natural products as sources of new drugs from 1981 to 2014. J Nat Prod. 2016;79(3):629-61. https://doi.org/10.1021/acs.jna tprod.5b01055.

2. Gurnani N, Mehta D, Gupta M, Mehta BK. Natural products: source of potential drugs. Afr J Basic Appl Sci. 2014;6(6):171-86.

3. Renslo AR. Antimalarial drug discovery: from quinine to the dream of eradication. ACS Med Chem Lett. 2013;4(12):1126-8. https://doi.org/10.1021/ ml4004414.

4. Fernández-Álvaro E, Hong WD, Nixon GL, O'Neill PM, Calderón F. Antimalarial chemotherapy: natural product inspired development of preclinical and clinical candidates with diverse mechanisms of action. J Med Chem. 2016;59(12):5587603. https://doi.org/10.1021/acs.jmedchem.5b01485.

5. Willcox M, Bodeker G, Rasoanaivo P, Addae-Kyereme J. Malaria control in africa and the role of traditional medicine. In: Willcox $M$, Bodeker $G$, Rasoanaivo P, editors. Traditional medicinal plants and malaria. Boca Raton: CRC Press; 2004. p. 1-19.

6. Abirami A, Nagarani G, Siddhuraju P. In vitro antioxidant, anti-diabetic, cholinesterase and tyrosinase inhibitory potential of fresh juice from Citrus hystrix and C. maxima fruits. Food Sci Hum Wellness. 2014;3(1):16-25. https://doi.org/10.1016/j.fshw.2014.02.001.

7. Barrion ASA, Hurtada WA, Papa IA, Zulayvar TO, Yee MG. Phytochemical composition, antioxidant and antibacterial properties of pummelo (Citrus maxima (Burm.)) Merr. Against Escherichia coli and \& Salmonella typhimurium. Food Nutr Sci. 2014;5(9):749-58. https://doi.org/10.4236/fns.2 014.59085.

8. Buachan P, Chularojmontri L, Wattanapitayakul SK. Selected activities of Citrus Maxima merr. Fruits on human endothelial cells: enhancing cell migration and delaying cellular aging. Nutrients. 2014;6(4):1618-34. https://doi.org/10.3390/nu6041618.

9. Potdar VH, Kibile SJ. Evaluation of antidepressant-like effect of Citrus Maxima leaves in animal models of depression. Iran J Basic Med Sci. 2011;14(5):478-83.

10. Chowdhury MRH, Sagor MAT, Tabassum N, Potol MA, Hossain H, Alam MA. Supplementation of Citrus maxima peel powder prevented oxidative stress, fibrosis, and hepatic damage in carbon tetrachloride $\left(\mathrm{CCl}_{4}\right)$ treated rats. Evid Based Complement Altern Med. 2015;2015:598179.
11. Kundusen S, Gupta M, Mazumder UK, Haldar PK, Saha P, Bala A. Antitumor activity of Citrus maxima (Burm.) Merr. leaves in ehrlich's ascites carcinoma cell-treated mice. ISRN Pharmacol. 2011;2011:138737.

12. Yathiender S. A comparative study of antimicrobial activity of Citrus Maxima and Citrus Aurantium plant extracts. Int J Recent Sci Res. 2017;8(7):18507-9.

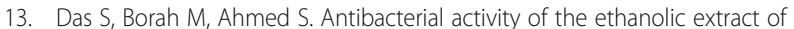
leaves of Citrus maxima (Burm.) Merr. On Escherichia coli and Pseudomonas aeruginosa. Asian J Pharm Clin Res. 2013;6(4):136-9.

14. Kundusen S, Gupta M, Mazumder UK, Haldar PK, Saha P, Bhattacharya S, et al. Antihyperglycemic effect and antioxidant property of Citrus maxima leaf in streptozotocin induced diabetic rats. Diabetol Croat. 2011;40(4):113-20.

15. Yetein MH, Houessou LG, Lougbégnon TO, Teka O, Tente B. Ethnobotanical study of medicinal plants used for the treatment of malaria in plateau of Allada, Benin (West Africa). J Ethnopharmacol. 2013;146(1):154-63. https://doi.org/10.1016/j.jep.2012.12.022.

16. Gogoi N, Chetia D, Gogoi B, Das A. Multiple-targets directed screening of flavonoid compounds from citrus species to find out antimalarial lead with predicted mode of action: an in silico and whole cell-based in vitro approach. Curr Comput Aided Drug Des. 2021;17(1):69-82. https://doi.org/1 $0.2174 / 1573409916666191226103000$

17. Suseela V, Gopalakrishnan VK, Chandrapraba D. Evaluation of free radical scavenging potential of ethanolic extract of Artemisia nilagirica (Clarke) Pamp. Leaves. Biosci Biotechnol Res Asia. 2009;6(1):189-95.

18. Suseela V, Gopalakrishnan VK, Varghese S. In vitro antioxidant studies of fruits of Artemisia nilagirica (Clarke) Pamp. Indian J Pharm Sci. 2010;72(5): 644-9. https://doi.org/10.4103/0250-474X.78538.

19. Bhat MY, Gul MZ, Khan N, Qureshi IA, Ghazi IA. Cytoprotective activity and anti-inflammatory properties of Artemisia nilagirica (Clarke) extracts- a study with macrophages. J Biol Act Prod from Nat. 2017;7(3):228-44.

20. Gul MZ, Chandrasekaran S, Manjulatha K, Bhat MY, Maurya R, Qureshi IA, et al. Bioassay-guided fractionation and in vitro antiproliferative effects of fractions of Artemisia nilagirica on THP-1 cell line. Nutr Cancer. 2016;68(7): 1210-24. https://doi.org/10.1080/01635581.2016.1205900.

21. Ahameethunisa AR, Hopper W. Antibacterial activity of Artemisia nilagirica leaf extracts against clinical and phytopathogenic bacteria. BMC Complement Altern Med. 2010;10(1):6. https://doi.org/10.1186/1472-6882-1 $0-6$.

22. Gul MZ, Bhat MY, Maurya R, Qureshi IA, Ghazi IA. In vitro evaluation of antioxidant and antiproliferative activities of Artemisia nilagirica extracts. Indian J Pharm Sci. 2017;79(6):872-84.

23. Devmurari VP, Jivani NP. Anticancer evaluation of Artemisia nilagirica. Int J Pharm Tech Res. 2010;2(2):1603-8.

24. Sahu N, Meena S, Shukla V, Chaturvedi P, Kumar B, Datta D, et al. Extraction, fractionation and re-fractionation of Artemisia nilagirica for anticancer activity and HPLC-ESI-QTOF-MS/MS determination. J Ethnopharmacol. 2018; 213:72-80. https://doi.org/10.1016/j.jep.2017.10.029.

25. Naik SK, Mohanty S, Padhi A, Pati R, Sonawane A. Evaluation of antibacterial and cytotoxic activity of Artemisia nilagirica and Murraya koenigii leaf extracts against mycobacteria and macrophages. BMC Complement Altern Med. 2014;14(1):87. https://doi.org/10.1186/1472-6882-14-87.

26. Panneerselvam C, Murugan K, Kovendan K, Kumar PM. Mosquito larvicidal, pupicidal, adulticidal, and repellent activity of Artemisia nilagirica (family: Compositae) against Anopheles stephensi and Aedes aegypti. Parasitol Res. 2012;111(6):2241-51. https://doi.org/10.1007/s00436-012-3073-9.

27. Panda S, Ranjit MR, Sahoo SL, Pati P, Sahoo R. Larvicidal, pupicidal, adulticidal and repellent activity of Artemisia nilagirica (C.B. Clarke) Pamp against malarial vector Anopheles stephensi. Adv Life Sci. 2016;5(511):4424-8.

28. Verma RP, Subburaju T, Balakrishnan N. Larvicidal activity of Artemisia nilagirica (Clarke) Pamp. And Ocimum sanctum Linn. A preliminary study. J Nat Remedies. 2006;6(2):157-61.

29. Panda S, Rout JR, Pati P, Ranjit M, Sahoo SL. Antimalarial activity of Artemisia nilagirica against Plasmodium falciparum. J Parasit Dis. 2018;42(1):22-7. https://doi.org/10.1007/s12639-017-0956-9.

30. WHO guidelines on good agricultural and collection practices (GACP) for medicinal plants. World Health Organization. 2003. https:/www.who.int/ medicines/publications/traditional/gacp2004/en/. Accessed 1 Dec 2020.

31. Singh J. Maceration, percolation and infusion techniques for the extraction of medicinal and aromatic plants. In: Handa SS, Khanuja SPS, Longo G, Rakesh DD, editors. Extraction technologies for medicinal and aromatic plants. Trieste: ICS-UNIDO; 2008. p. 67-82. 
32. Trager $W$, Jensen JB. Human malaria parasites in continuous culture. Science. 1976;193(4254):673-5. https://doi.org/10.1126/science.781840.

33. Kumawat MK, Chetia D. Synthesis, antimalarial activity evaluation and molecular docking studies of some novel dispiro-1,2,4,5-tetraoxanes. Bangladesh J Pharmacol. 2015;10(4):917-23. https://doi.org/10.3329/bjp.v1 $0 i 4.24532$.

34. Lambros C, Vanderberg JP. Synchronization of Plasmodium falciparum erythrocytic stages in culture. J Parasitol. 1979;65(3):418-20. https://doi.org/1 $0.2307 / 3280287$.

35. Pandey AK, Sharma S, Pandey M, Alam MM, Shaquiquzzaman M, Akhter M. 4, 5-Dihydrooxazole-pyrazoline hybrids: synthesis and their evaluation as potential antimalarial agents. Eur J Med Chem. 2016;123:476-86. https://doi. org/10.1016/j.ejmech.2016.07.055.

36. Lima RBS, Silva LFR, Melo MRS, Costa JS, Picanço NS, Lima ES, et al. In vitro and in vivo anti-malarial activity of plants from the Brazilian Amazon. Malar J. 2015;14(1):508. https://doi.org/10.1186/s12936-015-0999-2.

37. Mosmann T. Rapid colorimetric assay for cellular growth and survival: application to proliferation and cytotoxicity assays. J Immunol Methods. 1983;65(1-2):55-63. https://doi.org/10.1016/0022-1759(83)90303-4.

38. Seca AML, Pinto DCGA. Biological potential and medical use of secondary metabolites. Medicines. 2019;6(2):66. https://doi.org/10.3390/medicines6020066.

39. Mahire SP, Patel SN. Extraction of phytochemicals and study of its antimicrobial and antioxidant activity of Helicteres isora L. Clin Phytoscience. 2020;6(1):40. https://doi.org/10.1186/s40816-020-00156-1.

40. Ram M, Abdin MZ, Khan MA, Jha P. HPTLC fingerprint analysis: a quality control for authentication of herbal phytochemicals. In: Srivastava M, editor. High-performance thin-layer chromatography. Berlin: Springer; 2011. p. 10516. https://doi.org/10.1007/978-3-642-14025-9_7.

41. Itankar P, Sawant D, Tauqeer M, Charde S. High performance thin layer chromatography fingerprinting, phytochemical and physico-chemical studies of anti-diabetic herbal extracts. AYU. 2015;36(2):188-95. https://doi. org/10.4103/0974-8520.175546

42. Goswami AK, Gogoi N, Shakya A, Sharma HK. Development and validation of high-performance thin-layer chromatographic method for quantification of berberine in rhizomes of Coptis teeta wall, an endangered species collected from Arunachal Pradesh. India J Chromatogr Sci. 2019;57(5):411-7. https://doi.org/10.1093/chromsci/bmz009.

43. Tse EG, Korsik M, Todd MH. The past, present and future of anti-malarial medicines. Malar J. 2019;18(1):93. https://doi.org/10.1186/s12936-019-2724-z.

44. Pan WH, Xu XY, Shi N, Tsang SW, Zhang HJ. Antimalarial activity of plant metabolites. Int J Mol Sci. 2018;19(5):1382. https://doi.org/10.3390/ijms1 9051382.

45. Ouattara LP, Sanon S, Mahiou-Leddet V, Gansané A, Baghdikian B, Traoré ASA, et al. In vitro antiplasmodial activity of some medicinal plants of Burkina Faso. Parasitol Res. 2014;113(1):405-16. https://doi.org/10.1007/s0043 6-013-3669-8.

46. Cytotoxicity: in vitro determination. World Health Organization. https:// www.who.int/tdr/grants/workplans/en/cytotoxicity_invitro.pdf. Accessed 5 Dec 2020.

47. Panda SK, Das R, Leyssen P, Neyts J, Luyten W. Assessing medicinal plants traditionally used in the Chirang reserve forest, Northeast India for antimicrobial activity. J Ethnopharmacol. 2018;225:220-33. https://doi.org/1 0.1016/j.jep.2018.07.011.

\section{Publisher's Note}

Springer Nature remains neutral with regard to jurisdictional claims in published maps and institutional affiliations.

\section{Submit your manuscript to a SpringerOpen ${ }^{\odot}$ journal and benefit from:}

- Convenient online submission

- Rigorous peer review

- Open access: articles freely available online

- High visibility within the field

- Retaining the copyright to your article

Submit your next manuscript at $\boldsymbol{\nabla}$ springeropen.com 